\title{
Remarks on Human Biological Enhancement
}

\author{
Henry T. Greely*
}

INTRODUCTION

The area of law and biology, or the biosciences broadly, is an explosively growing area, and is an area that has potentially explosive consequences, both legally and politically. We may call it different things. At Stanford, we have a Center for Law and the Biosciences rather than a Biolaw Center, but our student group involved in this is called BioLaw. And we may focus on somewhat different things. We are hosting a conference in December 2008 on neuro-imaging, pain, and the law in order to explore the impacts of neuroscientific discoveries on the law. But in many different places, people are beginning to realize that our vastly expanded knowledge about biological systems, particularly, but not exclusively, human biological systems, is and will continue to have increasing consequences for the law.

Today, I would like to talk about one of those areas - the area of human biological enhancement. I am sure that Dean Agrawal here at Kansas Law is happy to see another former clerk for Judge John Minor Wisdom. I know she will enhance the Kansas Law School during her tenure here as Dean, and nobody worries about that because enhancement is generally a good thing. To enhance means to improve or to make better. But when we talk about human biological enhancements, people become much more concerned, and the controversies are much greater. I can sum up the reason in one name: Barry Bonds. People are concerned, not only in the area of sports, but also in the context of broader social and biological areas. People are concerned about intentional modifications of human biology as a result of scientific developments, and that concern has prompted an awful lot of heat. My argument is that thus far it has not prompted as much light as it should

\footnotetext{
Deane F. and Kate Edelman Johnson Professor of Law, Professor (by courtesy) of Genetics, Stanford University. These remarks were originally given at The University of Kansas School of Law on November 9, 2007, as part of the Kansas Law Review's Biolaw Symposium. These remarks build upon a previously published article, Henry T. Greely, Regulating Human Biological Enhancements: Questionable Justifications and International Complications, 4 SANTA CLARA J. INT'L L. 87, 105 (2006).
} 
have; there has been much more heat than light. And so, this talk is part of an effort, over several years, to try to shed more light into this tricky area. I have been working for fifteen years on legal, ethical, and social issues in genetics, then in embryonic stem cell research, and most recently in neuroscience. I have found that in each of these three areas, this issue of enhancement keeps coming up - different technologies, but the same or very similar set of questions.

Today I will talk about human biological enhancement. First, I will very briefly provide four examples of enhancing technologies. Second, I will present four general observations concerning human enhancement. Third, I will present six concerns, some of which I think are more valid than others. And then finally, I will give some proposed legal and policy conclusions of what we should do about human biological enhancement.

\section{ENHANCEMENT TECHNOLOGIES}

"Human biological enhancement" is a change to the human body that we do intentionally for the purpose not of making the disabled or the sick normal, healthy, or well, but of making healthy people better than well or of making disabled people not just normal, but beyond normal. In other words, it is using things not only to repair or bring up the human norm, but also to surpass either the preexisting position or to go to the extreme - to move outside the normal human range. There are at least four interesting technologies, already around to some extent, that provide human enhancements in controversial ways: 1) cosmetic surgery, 2) sports technologies 3) genetic technologies, and 4) neuroscience technologies. I am going to quickly run through each of these.

\section{A. Cosmetic Surgery}

The first category is cosmetic surgery. It has been around for a long time and developed, as reconstructive surgery, in efforts to repair those terribly wounded in World War I. As cosmetic, and not reconstructive, surgery, it first became popular in the United States with rhinoplastiesnose jobs. There is a nice irony there. When rhinoplasties first started in the 1910s and 1920s, people wanted long aquiline noses, similar to Roman noses, and then very quickly the fad changed and people wanted short, button noses. The first people who got nose jobs actually ended up, ten or fifteen years later, regretting that they had moved from what is now the favored affection to something different.

In recent years, we have experienced an explosion of cosmetic surgeries and cosmetic procedures of various types, including 
liposuction. But cosmetic surgery is an area where a tool originally developed for medicine was used to enhance people who were not sick or injured, but instead who were healthy and normal. The goal was not to cure, but, at least in the patients' minds, to enhance - to make them better than they were before.

\section{B. Sports Technologies}

With sports technologies, we are talking about pills or shots-largely about FDA-approved drugs and biologics. The one that came about first, that people have known about for the longest period of time, is the class of drugs known as anabolic steroids. Anabolic steroids help build muscle mass and decrease the recovery time from injury. A second drug, one of the earliest of the protein-based biotechnology products, is human growth hormone, which has very similar positive effects to anabolic steroids. A third is erythropoietin, another one of the earlier biotechnology drugs. Erythropoietin is a drug used for the treatment of anemia in people with kidney disease or people who have been treated for cancer. It increases the amount of red blood cells in blood, enhancing an endurance athlete by increasing the amount of oxygen in your system, keeping your muscles better oxygenated, and thus, for instance, allowing you to cycle longer if you are a competitive cyclist or run farther if you are a marathoner. Basically, it keeps your muscles in better shape.

Surgical enhancements also are possible. One of the more interesting is LASIK eye surgery, which is usually used just to take your vision from below normal to normal. It can also be used to take your vision above normal. You can ask your surgeon to see how sharp he can make your vision, for instance, by not only taking it just to 20/20, but to try to take it to $20 / 15,20 / 10$, or even 20/8. Athletes are getting LASIK surgery. Usually they are athletes who have myopia or some other kind of eye problem. They are also using LASIK to get rid of contact lenses while making their vision as sharp as they possibly can. The procedure, for them, is both curative and enhancing in one step.

\section{Genetic Technologies}

Two new types of technologies, genetic-selection and genetictransfer technologies, are a little more complicated. We have to consider two different aspects of genetic enhancement. One is genetic selection, which allows you to choose the genes of your offspring from among the preexisting genes and alleles that you and your spouse have. We have been able to do this for decades through amniocentesis, or chorionic villi 
sampling, both of which involve genetic testing of a fetus to allow the parents to make the decision about whether to terminate the pregnancy or not. A more interesting form of this technology, which has actually been around since 1989, although almost no one knows about it, is preimplantation genetic diagnosis, where people who are going through in vitro fertilization are able to test the eight-cell embryos that they have made. Assume that a man and a woman have successfully combined to make ten embryos. After three days, those embryos each are made up of eight cells. One can pluck, successfully and safely, one cell away from that eight-celled embryo and do genetic testing on that cell. Would that embryo, if it grew up, have cystic fibrosis? Would it have Huntington's disease? Would it likely be viable at all? Does it have the right number of chromosomes? Would it be a tissue match for a sibling who needs a bone-marrow or cord-blood transplant? Approximately seven thousand of these pre-implantation genetic-diagnosis cycles are happening every year in the United States right now. In fact, thousands of children have been born through this procedure over the last eighteen years, and none of them is missing one-eighth of his or her body. It is a successful procedure. This technology, however, only allows you to pick from the genes and alleles that the parents have to contribute, so if you have two blond parents, they are not going to be able to produce a brown-haired kid. They do not have the alleles for brown hair themselves.

The second of these technologies is not just a selection technology, but a gene-transfer technology that would allow you to transfer human genes into your body, such as existing wild-type human genes (uncommon but desirable genes) or (somewhat recklessly and futuristically) synthetic, "unnatural" human genes. A wild-type or synthetic gene could be transferred into an embryo, fetus, young child, or adult. For instance, the use of genetic-transfer technologies on athletes would involve adults who insert genes into their muscle tissue in order to strengthen those muscles. Moving a new gene in, whether it is a copy of an existing human gene or whether it is potentially a "new and improved" gene, could be done at all stages of an individual's development. Although most of that technology is not really ready right now, eleven children have been cured of severe combined immunodeficiency, or at least one of the forms of severe combined immunodeficiency, through the use of genetic-transfer technologies. As a result of the gene transfer, four of them have contracted leukemia, and two of them have died. That is the best result we have achieved. That does not mean that it will not improve. It is just not ready yet. 


\section{Neuroscience Technologies}

The fourth category is neuroscience. Many of you will have had at some point during the day today a neuro-stimulating and cognitively enhancing beverage containing caffeine. Some of you this evening will probably have an enhancing beverage, maybe not cognitively enhancing, of another sort containing alcohol. Humans have used various food substances for many years, from alcohol to caffeine to chocolate in order to change how their brain works, but now we are able to do it better.

There are, for example, two drugs known as Ritalin and Adderall, which are widely prescribed for people with attention-deficit disorder (“ADD") or attention-deficit-hyperactivity disorder ("ADHD"). These drugs are stimulants that have the somewhat counter-intuitive effect of calming down the children with these disorders who appear to be overstimulated. But they also work as stimulants for people who do not have ADD and ADHD. One hears of high school and college, and possibly even law school, students who do not have ADD or ADHD and do not have a prescription for Adderall or Ritalin, but who get the drugs from their friends who have the prescriptions. They then use them not as recreational drugs, but as study drugs, higher-tech equivalents of NoDoz or the seventeen cups of coffee that would otherwise get you through that all-nighter to finish your paper on time.

Another drug, approved by the FDA in 1997, is called Provigil (generically known as modafinil). It is another alertness drug. You take it, and it keeps you awake. How well you stay awake varies from person to person. Some people stay awake, alert, and fully capable for many extra hours. For most people, Modafinil does not have that strong of an effect. I have not yet heard of students taking Modafinil for all-nighters, but some academics take it when they are jet-lagged after flying to Europe or Asia for a conference. Also, some physicians take it when they are on night-call. They have to get a prescription from a doctor, but thanks to the off-label use doctrine, the physician is able to prescribe it for any purpose, whatsoever. There are clinical trials right now for a set of drugs that aim to improve the ability of people with early stage dementia to make, retain, and retrieve memories. We do not yet know whether they will work or not. I think one of them is in Phase III of the FDA approval process and a couple of them are in Phase II. None of them has come out yet. Assume for a moment that they work. Further assume that, like Modafinil, Ritalin, and Adderall, they are initially prescribed for people with a disease. Also assume that this set of new drugs works on normal, healthy people. Do we allow sophomores taking organic chemistry as part of their pre-medical curriculum to take memory 
pills so they can remember all those organic chemistry formulas, structures, and equations? Do we let law school graduates studying for the bar exam take memory pills so they can remember the Rule Against Perpetuities (not that it will do them a lot of good)? Those sorts of enhancements are on the horizon: cognitive enhancements. Neuroscience technologies are not all pills. Recent research has begun to indicate that if you do deep brain stimulation in a particular region of the thalamus, very deep in the brain, that people to whom this is done do not get tired. They are able to go on. It is like Modafinil squared. Some non-human primate subjects are able to go on for over a week without showing signs or consequences of fatigue. The military is apparently quite interested in this technology for its use among soldiers. I am not sure that law students would allow electrodes to be implanted in their brains to help them pass the bar exam - but I am not sure they would not. I am pretty sure some pre-medical students would do it to get though organic chemistry. These kinds of enhancing technologies are on the horizon, these things that make our brains function better. They are happening and will continue to happen at a greater rate.

\section{THOUGHTS \& CONCERNS}

I will now discuss four general thoughts about enhancement technologies before discussing the six major concerns that people tend to have about human enhancements.

\section{A. Four General Thoughts about Enhancement Technologies}

1. First General Thought: Medicine Is the Major Source of Enhancement Technologies

Notice that the source for every technology that I have talked about is medicine. The desire to help the sick, injured, disabled, and ill is the driving force. That is what led to these pills, these drugs being discovered, being tried through clinical trials with high expense, and being marketed. The cosmetic surgeries did not get started to give people nose jobs. Cosmetic surgery got started to patch up veterans of wars, particularly World War I. There is no greater primer, no greater push in the progress of surgery, than wars. Cosmetic surgery started with patching up war veterans with serious, serious injuries. But once you approve and perfect the techniques for one purpose, they become dualuse techniques. Not in the biological and chemical warfare sense, but dual-use techniques in that most of them can be used for medicine and 
used for enhancement. And that makes it very difficult to try to shut off the techniques in development. There are strong human interests involved in allowing the development of these technologies. But we may have to worry about whether we can control their move from medical uses to enhancing uses.

By the way, there is another whole area of controversy about enhancement that I do not want to talk about: the health insurance, specifically, determining when a particular treatment qualifies as covered medical care versus when it qualifies as an uncovered enhancement. This issue of either statutory language, regulatory language, or often insurance contract language is a hot topic, but it is not my issue today. It is, however, another example of the overlap between medicine and enhancement.

\section{Second General Thought: We Accept Human Tools but Question Human Enhancement}

Why are we so worried about human biological enhancements, but we are not worried about human tools? I flew in from San Francisco yesterday, but my wings are not tired at all. I did things that humans cannot naturally do, but I did them using tools. I came from Kansas City to Lawrence this morning - about forty-five miles in forty-five minutes. Nobody can run that fast, and I certainly cannot run that fast. I did something unnatural, but I did it using a tool. But these tools, granted, are not part of me. They are detachable from me. On the other hand, I have been wearing glasses for about forty-seven years and they feel a lot more a part of me than my gall bladder does. Quite seriously, the glasses are me, in some very important way, but my appendix is not. I can live without my appendix, but I cannot survive without my glasses.

We are not concerned about the enhancement of human activities and abilities through tool use. We seem to be more concerned when it becomes part of the human body. And I would just note that there are also things that are even more on the borderline than my glasses. I think Blackberry users seem to be surgically attached to their Blackberries. My wife just got an iPhone and she loves it. She sleeps with it. She takes it into the shower. For the first time in her life, she is really cool. She walks down the street with her iPhone and people say, "Ooh, is that an iPhone? Can I look at it? Can I touch it?" That is an enhancement of her abilities that is almost connected to her body. My kids and their iPods clearly seem to be somewhere between tools and prostheses that are permanently connected to their bodies. But we almost never worry about human enhancement through tools. That is odd. 


\section{Third General Thought: Acceptable Forms of Enhancement Already Exist}

We already biologically enhance humans in many ways that we do not seem to be concerned with at all. Let us return to sports. Think about a simple sport - the one-hundred-meter dash. What could be simpler than running one hundred meters in a straight line? But in order to be a great sprinter, you not only need the luck to be born with good, sprinter genes, but you need to be trained, you need to be coached, you need to know the right way to come out of the blocks, you need to know the right way to pace yourself. You need to have a weight-training program to build your muscles, not just in general, but the right muscles in the right way to the right extent. You need a nutritional program to maximize your energy levels and minimize your excess weight. You need, sometimes, equipment. You want to have the best starting blocks; you want to have the best shoes; you want to have the lightest, least airresistant shorts possible. If you are a swimmer, you want to shave your legs; you want to actually modify your body, looking for that extra 0.01 second - or maybe it just serves as a placebo effect to make you think that you are 0.01 second faster. But either way, it is an enhancement and you are changing yourself. Many athletes use sports psychologists as well. All of those things are enhancements - the coaching, equipment, weight training, nutrition, and psychology. And I am willing to bet a lot of money that, if we could figure out who the best natural sprinter in the world is, and bring him out of whatever village or town he lives in, and put him on a track against a mediocre college sprinter, the college sprinter would crush him because the college sprinter has been enhanced. Enhanced not with drugs or genes, but with food, weight training, coaching, equipment, and all those other things.

We do not seem to be worried very much about enhancement as a general matter. We just worry about some sorts of enhancement.

Oh, and you may be thinking, "Well, you know, sports, we like sports, but it's not very important." Well, we do cognitive enhancement already. I am in the cognitive-enhancement business. That is my jobto enhance my students. I hope I do a good job. It is certainly what I try to do. We law professors in particular pride ourselves not just on telling students things, on teaching them statutes and doctrines and court names, but on teaching them how to think like lawyers. Some people might argue whether or not that is enhancing or damaging - and there is a clear argument to be had there - but whatever it is, it is changing law students. Just as Head Start changes little kids; just as parents who regularly read to their children instead of dropping them in front of the TV change their 
children; just as tutoring and prep courses change students. All these are methods of cognitive enhancement.

And now you may be saying, "Yeah, well, but that's just mental; it's not physical." But, in fact, everything mental is physical. If you remember a single word of what any speaker says today, it is because your brain has physically changed. Some of the connections between your neurons have become stronger, and some of the connections between your neurons have become weaker. There may have been some new connections made. That seems to be where memory comes fromphysical changes in the brain. Those are enhancements that we do not worry about at all. Why do we worry particularly about these new biological enhancements?

\section{Fourth General Thought: Effort Cannot Distinguish Acceptable from Unacceptable Forms of Enhancement}

Work or effort is not a bright-line divider between acceptable and unacceptable enhancements. People often say, "well, we're interested in work; we're interested in rewarding people for effort. And these enhancements are too easy. You don't have to do anything." There may be an argument there, but it is a vastly over- and under-inclusive argument. You can have many enhancements (or advantages) that you do not work for. For instance, you did nothing to deserve the genes you were randomly given by your parents. You did nothing to deserve the genes that allowed you to be a law student or a lawyer or that contributed to your above-average intelligence. That was not something that you worked for. Moreover, it is chance if you are an athlete and you happen to live in an area that has a good, strong athletic program; it is not really your own doing. But, in fact, even a lot of the more specific advancements that we approve of do not involve work, and a lot of the enhancements we do not approve of do involve work.

First, I am going to talk about enhancements that do not involve work. So let us go back to erythropoietin. Erythropoietin increases the oxygen-carrying capacity of your blood by increasing the number of red blood cells in your body. There are other ways to do that. You can be lucky enough to be born with genes that give you a lot of red blood cells. There is a fair amount of natural variation in red blood cell levels among humans. It seems to be genetic; it might be genetic, but it also might be for other reasons. But whatever the reason, you did not work for it. Or you can live in a location at high altitude. This will increase your blood's oxygen-carrying capacity. If you grow up in Tibet, or in the Bolivian Altiplano, or even in the Rockies, you will, on average, have 
significantly higher red blood cell levels than people who grew up at sea level. Or, and this is commonly done by athletes, you can live at higher altitudes and come down to train at sea level. Just living in the Rockies gives you an advantage in your blood's oxygen-carrying capacity. And last but not least is my personal favorite. You can buy, on the Internet from a variety of sources, a sleeping tent that will reduce the oxygen level in the air while you are sleeping. You can set the altitude for 5000, 8000 , or 12,000 feet, or whatever the tent allows. While you are asleep, your body compensates for the fact that you have less oxygen in the air by producing more red blood cells. That is a legal form of enhancement. Why should the altitude tent be allowed when injecting yourself with an FDA-approved drug, assuming you have a proper prescription for it, should be banned? What is the difference?

Many forms of human enhancement, however, require lots of work. I could not inject myself with steroids and human growth hormone and look like Arnold Schwarzenegger. But even if I could come close to looking like Schwarzenegger, I would have to put a heck of a lot of work into it. Steroids do not give you good muscles. Steroids take the results of your workouts and make them better. People who use steroids successfully work out very, very hard. They work out longer and harder than they otherwise could, and they get better results from it. But if they do not work out, then they do not gain any benefit. Now let us return to our hypothetical memory pill—so far hypothetical, but maybe not for long. You are not going to be able to take the memory pill and suddenly know the Rule Against Perpetuities. You are still going to have to study. Your studying may be more efficient, but you are still going to have to work. So work is not a bright-line divider between appropriate and inappropriate enhancements.

\section{B. Six Concerns about Human Biological Enhancement}

There are three concerns about enhancements that I think are relevant and appropriate. I think we have to worry about safety, coercion, and fairness. The next three concerns, integrity, long-term social effects, and the "yuck" factor, I am frankly less taken with, although I think they inform more of the public response.

\section{Safety}

Certainly we have heard a lot about safety with respect to steroids. And there are real safety concerns with erythropoietin. A fair number of cyclists have dropped dead from strokes or other things that you do not 
expect from well-conditioned twenty-eight-year-old athletes, probably because their blood had too many red blood cells. There are safety concerns with individual uses, but there is sort of a broader safety concern. If these things come through an FDA or an FDA-like process, they have been accepted as safe, but that safety is qualified in many ways. There are two very relevant qualifications for these purposes. First, it is safety in the context of a particular dose and dosing regimen. For instance, patients may receive anabolic steroids to help treat the aftermath of treatment for testicular cancer. They are male and they do not make any testosterone, so they need anabolic steroids, which basically are modifications of testosterone, in order to regain their health. Doctors will put patients on a particular dose and dose regimen. Athletes, weightlifters, and bodybuilders who take steroids actually seem to take them on a variety of different regimens, but they are not regimens that have ever been tested by the FDA, or tested by anybody scientifically. It is word-of-mouth, passed around gyms and locker rooms, concerning how much you should take and when. They have got all these complicated rules about cycling-going up and down in dosage - none of which has ever been subject to any scientific testing, none of which has been approved by the FDA, and none of which is known to be safe.

The second safety issue is even deeper in some respects. When the FDA approves a drug as safe, it approves it as safe for a particular use. For instance, a drug to treat metastatic pancreatic cancer that would make fifty percent of the people who take it drop dead instantly, and cure the other fifty percent, would be an incredibly safe drug. Ninety-eight percent of people with metastatic pancreatic cancer will otherwise be dead within a year. That is a wonderfully safe drug. If you use that to treat teenage acne, and half the people drop dead but the other half have wonderful skin, that is a terribly unsafe drug. This is a concern that some people may have with the off-label use of FDA-approved medicines. The enhancement uses will typically, but not always, be less important than the health uses. The ability to move from normal to fifty percent above normal is arguably less important than moving from fifty percent of normal to normal. And if the drug is originally approved as safe in the context of treating people who are sick in order to move them up to normal, then the cost-benefit analysis may look much different than if it is somebody who is already normal and just wants to get better than normal. There are special safety issues with enhancement that, even apart from the other reasons why we may not want to count on the FDA's assessment of safety, it particularly does not work with respect to 
enhancement uses of drugs or devices that are approved for medical purposes. That is a real concern with these enhancements.

\section{Coercion}

If biological enhancements were allowed, we might say they could be allowed for people who voluntarily choose to use them. But we might draw the line at frank, implicit, or most trickily, most complicatedly, parental coercion.

Let us first consider frank coercion. The military might order you to take amphetamines if you are going to fly a certain flight in order to enhance your ability to fly safely for a long period of time. Will we allow the military to order other enhancements, order soldiers to have electrodes put in their heads so they can be stimulated to stay awake forever? We might. It being the military, they have a strong argument for both the safety of the soldiers and the safety of the country. Would we allow employers to do it? Would we allow employers to insist on enhancements that are biological in nature? Well, we allow employers to insist on some things. I am about to go through a four-hour mandatory training program at Stanford for dealing with employees. We all have to go through it. That is expected to enhance me as a supervisor of other employees. Of course, I do not have to do it. But, even with tenure, I could be fired if I did not do it. I think they would start by fining me and so on, but ultimately, I have to do what the employer says. Should we allow employers to insist that their employees take memory pills if it is a job that involves memory?

Next, let us consider the complex question of implicit coercion, where people are not actually forced to do something; they are only forced to do it if they want to keep doing something they like. You hear this from bodybuilders and weightlifters already: "I'd love to not take steroids, but then I couldn't compete; I couldn't win; I couldn't be the best; I couldn't even show up in the big shows because everybody else is doing it." Imagine a pre-medical student who is taking organic chemistry, the gateway to medical school, knowing that the class is graded on a curve and not wanting to take memory pills, but believing that ninety percent of her classmates are taking memory pills. Does that person really have a choice? Yeah, she could choose not to be a doctor. Should we protect people from implicit coercion? Of course, implicit coercion is another word for competition, arguably, in this context. I do not have an answer to that question, but it is one we are going to have to deal with. 
The third part of coercion, and the form we do not think of as coercion, but is clearly coercion, and I say this as a parent of two, is parental coercion: the power parents exercise over their children. Our children do not give informed consent to do anything when they are five or even twelve years old. And even as teenagers they are particularly not competent to give consent or do anything else other than annoy their parents. But fundamentally children cannot make informed decisions; parents make decisions for them. One of my freshman advisees at Stanford, fifteen years ago, was a kid whose parents may have pushed him, and were certainly happy to let him, play as much golf as he wanted to. And he turned out to be Tiger Woods. Now, Tiger Woods certainly has lots of gifts; he is a very impressive guy. But he probably would not be Tiger Woods today if his father had not pushed him. Wolfgang Mozart had a musician father who pushed him as well. These parents were pushing their children toward enhancements; they were pushing them farther than other children got pushed. But we all know of stories like that of the ex-quarterback, Todd Marinovich, stories of pushing gone wrong, where the father trained him from the cradle to be a quarterback and ended up with a drug-abusing, convicted, former quarterback instead.

Parental pushing has a long history; sometimes it works, sometimes it does not. Sometimes it is more outrageous, sometimes it is less. We all try to push our kids, that is, after all, our job: to try to coerce them into growing up to be good human beings. But is there a difference when it involves biological enhancements? If parents are convinced or if they read somewhere on the Internet that giving their children a particular drug from age three to age six will double their IQ or increase their chances of getting an 800 on all parts of the SAT by fifty-percent, should we let parents make those sorts of decisions when the children whom they are pushing cannot consent themselves? Coercion-frank coercion, implicit coercion, and parental coercion - raises real questions.

\section{Fairness}

Fairness works at a couple of different levels here. One level is the individual competition, for instance, the individual weightlifter, wrestler, or bodybuilder, or even the individual football player who is trying to make it to the NFL. Is it fair that one competitor is using drugs and the other is not? That is a significant question. But there is a deeper question concerning fairness across society.

What happens if only the rich or only certain groups obtain access to these enhancements and other people do not? That raises large social- 
equity questions. Now, to raise those questions is not necessarily to say we have to abandon enhancements because of them. One could imagine free enhancements for everybody or some other system that levels the playing field. But this issue of equity between individuals and across society is a very significant one, just as in other areas of our society, such as equitable access to education for children across class and racial lines. That is an important social concern, and it will not go away, but instead will only be exacerbated as we move into human biological enhancements.

\section{Integrity}

There is not a good label for this next concern, but I guess I will call it "integrity." It is the concern that it is cheating to use enhancements, that it is not right somehow. Now if that were the equivalent of "the rules forbid it and you should follow the rules," then I agree. At least follow the rules to the extent that it is the norm within that competition to follow the rules. Every offensive lineman holds some on every block; every water polo player grabs under the water whenever he can. Some sports have a level of accepted cheating. Baseball pitchers do not report to the umpire every time they have a scuffed ball; they use it while they can. So there is some level of permitted cheating in most endeavors, but if it goes beyond that, if the rules say you cannot do this and those rules are enforced, you should not do it. That is the side of the integrity argument I have no question about.

But that does not answer the question about what the rules should be. And some people argue that, particularly in the sports context, enhancement violates the essence of sport; that using biological enhancements is inherently cheating or inherently violates the integrity of the endeavor.

I don't get it. Sports have arbitrary sets of rules that we make up. God did not say bases should be 90 feet apart, or a football field should be one hundred yards long. We tinker with rules regularly. You have a fair competition within whatever the rules are; you might want to change the rules to try to keep the competition fair. More likely, you change the rules to try to keep the audiences interested and paying the money to come see the competitions, but there is no Platonic Ideal of football, baseball, or track and field that everything has to be compared to. Therefore, competitors who are using biological enhancements cannot fall short of this Ideal. In any event, all those other sets of enhancements, such as uniforms, equipment, coaching, sports psychology, nutritional supplements, and weightlifting, probably violate 
it, too. So why pick on this kind of enhancement? I am not impressed by the integrity argument.

\section{Long-Term Social Effects}

The fifth argument comes from Michael Sandel, a political philosopher at Harvard who has written what I think is the best book arguing against human biological enhancements. Ultimately, I disagree with it, but it is balanced; he sees arguments on both sides. Sandel is worried about long-term social effects. He is worried that in a world where we enhance people, we will increase our discrimination against the non-enhanced or against those who are completely outside of enhancement: the sick, disabled, and unfortunate. If we are all focused on becoming Supermen and Superwomen, the people who are left behind will be left even further behind.

Sandel might be right, but he might be wrong. That is a difficult empirical assessment of how society will change. We drastically improved our approach to health, including mental health, over the last one hundred years, but, you know, looking back over the histories of mental healthcare in the nineteenth century, I do not think we are treating the insane worse now than we did 150 years ago. As we have become healthier, we are not treating the sick worse. Actually, we are generally treating them better. The Americans with Disabilities Act did not pass in 1843; it was passed in 1990, so I am not convinced that Sandel is right. I cannot prove that he is wrong, but for me, it is hard to justify taking serious actions to ban or limit enhancements based on a fear of social change that may or may not happen. Instead, we can monitor the effects as they occur or change social attitudes concerning certain enhancement technologies.

\section{The "Yuck" Factor}

The last category has the most political resonance, but the least intellectual substance. It is the "yuck" factor. As the concern goes, "it's wrong because it's just not right, because it's not natural." The intellectual versions of this come in two categories. There is the religious perspective: that this is not how God meant us to be. This concern always strikes me as not entirely convincing, especially when it is delivered by people who have taken an airplane to give their talk, are being filmed by video cameras and are using PowerPoint. Now, the Amish might be able to make that argument, even the Amish use a lot of things that were not around in biblical times. Most of us really cannot 
make an argument from divine intent very well. Everything about human life is different from what it was 10,000 years ago. If there were an Adam and Eve, everything about the way we live today is different from how they lived.

The other, the secular version of that argument - although I hesitate to call it secular, maybe the pantheistic version-is that this is not the way evolution intended us to be. This is not the way natural selection created us, natural selection knew what it was doing, and therefore, we should not muddle with it. Well, that argument has a couple of problems. So far as we know, natural selection does not have a goal, plan, or direction. One hundred years from now, we (or "they") may conclude that natural selection really liked cockroaches because that may be all that is left in terms of land animals - the ones who were able to survive global warming and nuclear war.

Furthermore, we are so far from what we were naturally that focusing on the past results of natural selection does not work either. As a species, we continue to evolve. We see it in things like diseases, such as our resistance and susceptibility to different diseases, and the diseases' interaction with and susceptibility to us. These changes occur over long periods of time. A lot of our common epidemic diseases seem to have evolved about 10,000 years ago, about the time humans made the biggest change in our history and moved from being hunter-gatherers to agriculturalists. Through our culture we are constantly changing the effects of natural selection on us, maybe in a big way, but I suspect in a small way. Nonetheless, we are not a fixed end of natural selection as to which any sort of interruption is wrong. I frankly do not see much intellectual meat in the naturalist argument, the "yuck" argument. If somebody wants to tell me, "God has told me that this is wrong," I will not be able to argue with him on that, and if he sincerely believes it, more power to him, but unless or until God tells me that, I am not likely to take that position.

In summary, I think there are three arguments that deserve a lot of attention: the safety, coercion, and fairness arguments. As for the three other common arguments, the integrity, long-term social effects, and the "yuck" arguments, I frankly do not see much in them, although I am (somewhat) open to being convinced.

\section{HUMAN ENHANCEMENT \& THE LAW}

Now, since this is a biolaw conference, let me say a very little bit about the law. I do not think the law is terribly relevant here right now, although it could be. Many of these enhancements could be and 
potentially are within the jurisdiction of the Food and Drug Administration ("FDA"), which regulates products that "affect structure and or any function of the body of man or other animals," such as drugs and medical devices. The FDA, to the extent that these enhancements work by affecting the structure and function of human bodies (including brains), could take jurisdiction of them. The FDA, however, does not always extend its jurisdiction to the far reaches of the statute. For instance, clothes affect the structure and function of humans, but the FDA has yet to rule on sneakers or high heels. High heels, quite frankly, should be gone if the FDA had anything to say about it in terms of safety. So there is no guarantee that the FDA would take on all of these enhancement technologies. The FDA would probably get most of these, though, because they will come about through medical applications of drugs and devices. Surgical procedures are within the FDA's regulatory authority because the FDA does not regulate procedures. But to the extent people need to use new devices or new drugs for the procedure, they will probably come within the FDA's overview. It will be interesting to see how the FDA chooses to regulate enhancements.

What would be the results of a cost-benefit analysis when weighing not a specific disease, but weighing a more general enhancement? I think the only clearly enhancing things that the FDA has taken jurisdiction over are tinted, cosmetic contact lenses. The FDA initially considered these medical devices, but then, in 2003, reclassified them as "cosmetics," eliminating advance safety review. Congress passed a statute in 2005 requiring that they be treated as medical devices, despite the fact that they were more cosmetic rather than actual medical devices. Even though the contacts were not being used for medical purposes, they do affect the function and structure of the eye and they do raise safety concerns, especially if not provided by a trained professional.

The tinted contact lenses are a nice example of the complexity of how the FDA treats enhancers. The FDA could regulate all enhancers, but it will be complicated; it would have some issues to work out. And then you still have the problem of off-label use. If something is approved for medical purposes and you can find a doctor who is willing to prescribe it to you for a non-medical, enhancing purpose, the FDA has nothing to say about it, apart from some limits on promotion and marketing of the off-label use.

Congress can change that. For example, Congress explicitly declared off-label use of human growth hormone illegal. (Actually, Congress first started with anabolic steroids before reclassifying them by statute as a controlled substance. Then, Congress simply substituted human growth hormone in that section of the statute for the words 
"anabolic steroids.") Congress can limit off-label use, and Congress can force the FDA to limit off-label use, but under the existing Act, the FDA has no general power to impose such limits. Congress can do a lot of these things, but there are real political limits on Congress's and the state legislatures' abilities to act.

There may also be some constitutional limitations. I think the constitutional limitations with respect to adults would require a substantial stretch in our existing law, but I am not sure what constitutional limitations there might be with respect to the parent-child relationship. The state cannot say, "Parents, you can't send your children to private schools," because there is Supreme Court precedent for the constitutionally protected power of parents to make some fundamental decisions about their children's upbringing. That power might be implicated here. Overall, the constitutional issues seem unlikely to be very strong, with the possible exception of children. Congress probably has the power to regulate human enhancements, but should it, would it, will it?

There are also some de facto limits caused by the fact that the U.S. is not the only country in the world. If the U.S. bans a drug for enhancement, customers could then go to Mexico or to an off-shore human-enhancement center, perhaps in the Grand Cayman Islands. The U.S. does not control the whole world. And the whole world is never going to agree. Even if you could get ninety or one hundred countries to agree, you will find some of the world's 190 or so countries will not.

\section{CONCLUSION}

So what should be done? I am, by my own personality, driven to take a middle position where people can shoot at me from both sides. I think human-enhancement technologies are not altogether good, but not altogether bad. Trans-humanists may not like me - the people who are eager to be beamed into their stainless steel bodies and move on beyond humanity-because I think society does have some significant concerns that could lead to regulatory limitations on human biological enhancements. Particularly, the safety issue is very serious; the coercion issue may require action; and the fairness issue, both in individual competitions and across society, demands attention. Sometimes that attention may be bans; sometimes that attention may be truth in advertising regulation; sometimes it may be giving people a choice so that they can have the steroid-free football league or the "XFL," the steroid enthusiasts' football league. We could require choices of that nature. 
There are lots of interventions other than just a complete ban or complete non-ban. For instance, the government could provide subsidies or require free provision of enhancements that are particularly important to people who want them but cannot afford them. On the other hand, I do not see why the government should intervene on the last three issues - on the integrity, long-term social effects, or "yuck" issues. I am perfectly happy to let individuals or groups of individuals make their own decisions. For instance, I am perfectly happy to let professional sports leagues, the NCAA, or medical schools regulate themselves. A medical school could say, "We'll accept only grades from students who were certified as not taking memory pills when they took the classes, and who have test results to prove it." If private schools, public schools, individual schools, or groups of schools want to make their own rules, then that is okay. But I do not see a strong argument for government intervention now.

On balance, like most things, human biological interventions can do some good. They can do some harm. I am concerned that we will let them go so far that the harms to individuals or societies will grow out of hand. I am also concerned that we will stop them prematurely so that the benefits the technologies could bring to individuals, both sick individuals and individuals who genuinely want to improve themselves, are not allowed because of speculative and uncertain fears about the future. We need to think about enhancements intelligently. We need to have a conversation about them. And, ultimately, we need to regulate human enhancements in ways that will maximize their benefits and minimize their harms. 